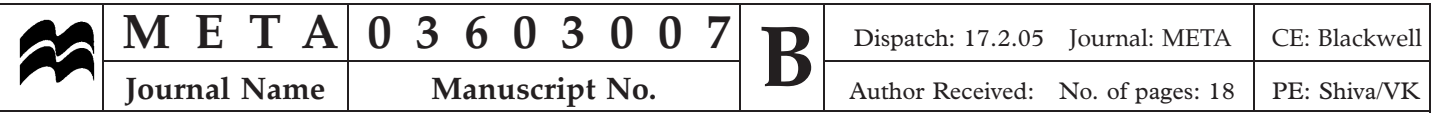

(C) Metaphilosophy LLC and Blackwell Publishing Ltd. 2005.

Published by Blackwell Publishing Ltd, 9600 Garsington Road, Oxford OX4 2DQ, UK and 350 Main Street, Malden, MA 02148, USA

METAPHILOSOPHY

Vol. 36, No. 3, April 2005

0026-1068

\section{INTUITIONS AND SEMANTIC THEORY}

\author{
HENRY JACKMAN
}

\begin{abstract}
While engaged in the analysis of philosophically central concepts, analytic philosophers have traditionally relied extensively on their own intuitions about when such concepts can be correctly applied. Intuitions have, however, come under increasingly critical scrutiny of late, and if they turned out not to be a reliable tool for the proper analysis of our concepts, then a radical reworking of analytic philosophy's methodology would be in order. One influential line of criticism against the use of intuition argues that they only tell us about our conceptions of things, and not the things themselves. This venerable line of criticism can seem considerably strengthened if one endorses "externalist" accounts of meaning. Nevertheless, the move from semantic externalism to the rejection of intuitions will be shown to be illegitimate if one has a constitutive rather than expressive understanding of the relation between our intuitions and our concepts.
\end{abstract}

Keywords: conceptual analysis, externalism, intuitions.

\section{Introduction}

While engaged in the analysis of such topics as the nature of knowledge, meaning, and justice, analytic philosophers have traditionally relied extensively on their own intuitions about when the relevant terms can, and can't, be correctly applied. ${ }^{1}$ The preferred analysis of such terms has been assumed to be that which would bring all of our (sometimes conflicting) intuitions into a type of "equilibrium."2 Consequently, if intuitions about possible cases turned out not to be a reliable tool for the proper analysis of philosophically central concepts, then a radical

${ }^{1}$ Hence the vast literature about "what we would say" about "Twin Earth," "Trolley cases," "Gettier cases," and the like. Intuitions of this sort consist primarily of our dispositions to make judgments about the application of terms to particular cases. Intuitions are thus not here taken to be the product of a special faculty in the mind, and certainly not a faculty whose proper use could be understood as infallible. It should also be clear that intuitions in the sense that one might have an "intuition" about whether a certain number will come up in a lottery are not at issue either. For a more extended discussion of the sense of "intuition" that is relevant here, see Pust 2000.

${ }^{2}$ This procedure finds its most influential formulation in Goodman 1954 and Rawls 1971.

(C) Metaphilosophy LLC and Blackwell Publishing Ltd. 2005 
reworking of philosophy's (or at least analytic philosophy's) methodology would seem to be in order. It should thus be no surprise that the increasingly critical scrutiny that intuitions have received of late has produced what has been referred to as a "crisis" in analytic philosophy. ${ }^{3}$ I'd like to argue here, however, that at least one influential line of criticism against philosophical appeals to intuition is not as serious as its proponents have claimed.

\section{Externalism and Intuitions}

The particular criticism of the use of intuitions in conceptual analysis that will be focused on here argues that contemporary "externalist" semantic theories show that philosophers' intuitions lack the sorts of connection to their subject matter needed for them to be reliable (even when the subject matter is conceived as the relevant concepts, or meanings, of the terms involved). ${ }^{4}$ If our concepts are determined by "external" factors, such as our social and physical environments, then there seems no reason to think that our intuitions about their proper conditions of application should be reliable. However, semantic externalism is itself a view that was initially motivated and defended largely on the strength of our intuitions about cases. ${ }^{5}$ Philosophers' reliance on intuitions in semantic theory may thus seem to be in tension with the sorts of semantic externalism that these intuitions support. Such criticisms can, I believe, be answered, and the resulting defense of the use of intuition in semantic theory should generalize to application of them to our other central philosophical concepts.

That semantic externalism could pose problems for the use of intuitions in philosophy should not be surprising, since the "internalist" theories of meaning that externalism displaced seemed ideally suited for underwriting traditional conceptual analysis. After all, the most natural objection to conceptual analysis is that it only tells us about, say, our conception of justice, and not justice itself. ${ }^{6}$ Internalist accounts of

${ }^{3}$ See DePaul and Ramsey 1998b, x, for a recent characterization of this development.

4 A second variety of criticism appeals to recent work in psychology to show that our intuitions are much less reliable than we frequently take them to be, and that our concepts may far less suitable for "analysis" (in terms of the necessary and sufficient conditions for their application) than philosophers have traditionally assumed. Criticisms of these sorts can be found, for instance, in the essays in DePaul and Ramsey 1998a, and such criticisms are discussed in Jackman 2004.

${ }^{5}$ For some doubts about the importance of such intuitions in establishing semantic externalism, see Laurence and Margolis 2003.

${ }^{6}$ For recent versions of this charge, see Cummins 1998, 124, and Kornblith 1998, 133. Goldman and Pust (1998) make a similar charge, but with a more upbeat view of the value of the descriptive analysis of our own concepts/conceptions. On their account conceptual analysis is in the business of describing, say, our concept or folk theory of meaning rather than meaning itself. I discuss reasons for being dissatisfied with this conception of conceptual analysis in Jackman 2004. 
meaning attempt to meet this objection by closing the gap between our concepts and what they are concepts of. For instance, if what we meant by "justice" were determined by something like the descriptions we associated with that term - and what "justice" referred to was simply whatever satisfied (most of) those descriptions - then it would be clear why conceptual analysis should give the philosopher intuitive access into the nature of justice. Philosophers' intuitions would simply be expressions of those meaning-constitutive descriptions that determined what their terms referred to. Intuitions would thus seem to have a strong prima facie claim to be true, and appeals to intuition would be a reliable method in determining the nature of knowledge, justice, or any other subject of philosophical discussion. ${ }^{7}$ This is not something unique to purely descriptive accounts of meaning. Any theory according to which meaning is entirely determined by introspectively accessible aspects of use will leave appeals to intuitions in pretty good shape.

However, in the mid-1970s Saul Kripke and Hilary Putnam highlighted a number of cases that seemed to show that the meanings of our terms were not determined by either the descriptions associated with them or any other introspectively accessible aspect of use (Kripke 1972, Putnam 1975). On these new "externalist" theories, then, the more "internal" connection between our conceptions of things and what we were, in fact, thinking about seemed to be broken. There was no guarantee that most of our beliefs about, say, "water" or "Gödel" had to be true, and things might be no different with concepts like "knowledge," "justice," and "meaning." 8 The internalist picture of meaning provided an explanation of why philosophers' intuitions were reliable, and with the demise of such internalist accounts, the status of such intuitions seems undermined.

\section{Intuitions in Semantic Theory}

The claim that semantic externalism compromises the use of intuitions in philosophy has been defended with respect to semantic theory itself in recent articles by Herman Cappelan and Douglas Winblad. ${ }^{9}$ These

\footnotetext{
${ }^{7}$ On "cluster" versions of the description theory (see, e.g., Searle 1967) some intuitions could be mistaken in virtue of failing to fit whatever satisfied the majority of the rest, but the point remained that intuitions were generally reliable, since they reflected the exclusive source of those facts that determined what we meant.

${ }^{8}$ While a number of authors (e.g., Burge [1988] and Davidson [1984]) have argued that externalism poses no problem for our knowledge of what the terms in our own language mean, the more "disquotational" sorts of self-knowledge that they present are not of the sort that would underwrite our ability to give any sort of analysis of the concepts we employ.

${ }^{9}$ Cappelan and Winblad 1999a and 1999b. I'll be focusing on these articles largely because they present a clear (and to my mind the most effective) attempt to work out the suggestion that semantic externalism undermines our justification for our use of intuitions in philosophy.
} 
authors claim that endorsing externalism about semantic terms like "meaning" and "reference" "serves as a basis for challenging the widespread assumption that intuitions about cases can legitimately be used as evidence for semantic theories" $(1999 \mathrm{a}, 344) .{ }^{10}$ This would be an awkward result for Kripke and Putnam, since they motivate their externalist accounts of meaning largely by appeals to our intuitions about cases. Cappelan and Windblad thus suggest that Kripke and Putnam's methodology presupposes a more traditionally "internalist" conception of meaning for the term reference itself. As they put it:

Kripke and Putnam attack the idea that what is in the mind determines the references of expressions such as "Gödel" or "water," but in so doing they rely heavily on appeals to intuitions. Since intuitions are generally thought to rest on access to inner states, this method seems to presuppose that what is in their minds determines the reference of "reference." [1999a, 338]

Such a presupposition, they go on to argue, runs afoul of the fact that precisely the same scenarios Kripke and Putnam use to criticize the justification of our beliefs about "water" or "Godel" can be developed for semantic terms like "reference" and "meaning."

For example, in Putnam's best-known argument, he asks us to imagine a Twin Earth exactly like ours, including duplicates of Earth's inhabitants, with the only difference being that what is called "water" on Twin Earth (while it shares all the superficial features of water) is not $\mathrm{H}_{2} \mathrm{O}$ but rather a substance that has a completely different chemical structure (called XYZ). The intuition Putnam draws on is that "water" would mean something different in the language spoken on Twin Earth from what it means in Earth English. Since the "psychological states" of people would be the same on both planets, ${ }^{12}$ the meaning of "water" seems not to be determined by what is "in the head" of the term's users. Cappelan and Winblad argue that an analogue of Putnam's Twin Earth case can be constructed for "reference":

Suppose Kripke has given a correct account of what reference is, one that correctly describes the extension of "reference" in the actual world. Now imagine a Twin Earth, exactly like ours, except that in it, the extension of "reference" fits Gareth Evans's theory of reference. On Earth, what is in the

${ }^{10}$ Cappelan and Winblad also believe that this argumentative strategy "can be extended to other areas of philosophy as well" (1999a, 337).

11 Some might consider this argument to be a sort of reductio of semantic externalism, but, as I will argue later, it is best understood as attempting to demonstrate a type of contradiction derivable from the sorts of "intuitive method" used to support such externalism. Cappelan and Widblad seem to understand it primarily in this latter way, though they discuss the possibility of the former strategy as well (1999a, 347).

12 Or at least the "narrow" states would have been the same in the eighteenth century of each. 
extension of "reference" are relations between words and the world in which certain expressions are connected to extralinguistic elements by causal chains that begin with initial "baptisms" or "dubbings." On Twin Earth, however what is in the extension of "reference" is different; typically, the relations in question are such that the expressions must be linked to the causal sources of the information associated with them. Just as the difference between XYZ and $\mathrm{H}_{2} \mathrm{O}$ manifest themselves only in unusual circumstances - such as under laboratory conditions - the differences between the expressions of "reference" on the two planets are not ordinarily different. [1999a, 338]

If there really were such Twin Earth cases where all the psychological states (and thus the intuitions) in both worlds were the same while "reference" itself was something different, then intuitions alone might not be a reliable guide to the nature of reference. However, a semantic analog of Twin Earth capable of seriously undermining the legitimacy of our semantic intuitions is much harder to develop than Cappelan and Winblad suggest.

First of all, it is crucial to Putnam's argument that it is fairly uncontroversial to assume that there could be a planet just like ours where what was called "water" had a chemical structure other than $\mathrm{H}_{2} \mathrm{O}$, but where all of the inhabitants' (narrow) attitudes or internal states were the same. ${ }^{13}$ By contrast, it is far less easy to understand how "reference" (or, for that matter, terms like "justice" and "knowledge") could mean something different in the two worlds even though the beliefs and reactive attitudes of all the speakers were the same in each. ${ }^{14}$

Cappelan and Winblad consider this sort of worry, and they are willing to admit that if "reference" were to mean something different in the two worlds, there must be some corresponding difference in the inhabitants' attitudes (1999a, 342). ${ }^{15}$ Nevertheless, they do not think that conceding that there must be some psychological difference between the inhabitants of a "Kripke world" and an "Evans world" 16 is enough to legitimate the use of intuitions in semantic theory, because

13 Though see Donnellan 1983 and 1990 for a dissenting view on the possibility of such cases.

${ }^{14}$ It would be like asking us to assume that moral reality has an essentially consequentialist structure in this world and then to imagine another psychologically indistinguishable from ours where the moral facts are deontological in nature. Facts about water seem comparatively sui generis, and this intuition is considerably weaker with moral and semantic facts. The intuition that such facts in some sense supervene on psychological facts, while certainly not uncontroversial, is still fairly widespread. Both moral and semantic facts are typically viewed as normative, and norms are best understood as standards that (in some sense) we set. This assumption is, of course, controversial as well (for a recent discussion of it, see Williams 2001, 170), but the arguments in the article do not depend on it.

${ }_{15}$ Cappelan and Winblad's concession is, admittedly, granted for the sake of argument.

${ }^{16}$ For the sake of brevity, I will be referring to a world where Kripke's account of reference is true as a "Kripke world" or a "K world," and to the language spoken in that world as a "K language." Worlds where Evans's account is true would be "E worlds, " and so on. 
the resulting disanalogy between our examples and Putnam's is significant in this context only if it implies that in order to use "reference" meaningfully, speakers need to have in their minds something that determines uniquely identifying conditions for what is in a term's extension. But this implication is not forthcoming. In particular, we see no reason to think that the presumed psychological differences underlying the differing conventions under discussion can not be spread out in time and across members of the linguistic communities such that... (a) The psychological differences do not affect [ the subject's] internal states at all ... (b) The psychological states are not such that philosophers need have any sort of special access to them ... (c) There need not be any single individual in the community who has complete knowledge of all the actions and intentions that make it the case that "reference" has the extension it has in that community. [1999a, 342-43]

Cappelan and Winblad thus suggest that even if there must be some psychological differences between a Kripke world and an Evans world, these differences need not be accessible to philosophers. However, could philosophers in a Kripke world really reach a point of general reflective equilibrium on the conclusion that they inhabited an Evans world? The emphasis here should be on the possibility of their having actually reached equilibrium on the topic, since there are many cases where the members of the community think they have reached this stage, but where they eventually turn out to be mistaken. For instance, while there may have been widespread agreement relating to semantic internalism before the 1970s, this was not because philosophers' views on that topic had actually reached equilibrium. Indeed, one way of reading Putnam's (1975) article was that he was pointing out an unperceived lack of equilibrium among philosophers' views. One can always legitimately challenge any widespread philosophical orthodoxy, since (as with Putnam's 1975 article) that challenge can take the form of suggesting that the orthodoxy is not in (wide) reflective equilibrium.

This is not to say that philosophers need have any privileged or special access to this sort of information, but it does not follow from this that we should think of them as plausibly shut out from it. ${ }^{17}$ The information may be spread out across the linguistic community, but it seems hard to imagine how philosophers could be completely insensitive to such differences. "Reference" is not, after all, a term like "electron" or "waltz," where there is some expert community to which philosophers and others can be expected to defer. Philosophers' intuitions are justified not because they are special but because they are instances of intuitions

17 And so one need not deny Cappelan and Winblad's claim (b) or, for that matter, (c).

18 Furthermore, it remains unclear why this wouldn't just result in philosophers meaning by the relevant terms something different from what others do. The possibility that philosophers might have such idiosyncratic concepts is a serious problem of its own, and it is discussed in more detail in Jackman 2001a and 2004. 
that are more widely shared. ${ }^{19}$ This is why the intuitions that carry the most weight are those that secure reflective agreement among members of the philosophical community.

To take a well-known example, the name Madagascar was originally applied to a part of the African mainland, but Marco Polo mistakenly took it to apply to the large island across from it, and his usage of the term persists today. If we spoke a K language, "Madagascar" would still refer (exclusively) to part of the African mainland, and not to the island bearing the name on most maps. ${ }^{20}$ Because they think that, in such cases, the term clearly changed its reference over time, most philosophers would assume (if they had to choose between the two) that that we spoke an E language rather than a $\mathrm{K}$ language. The philosophical community may just be idiosyncratic in this respect, and most nonphilosophers, when apprized of the history of the term, may actually think that it still refers (exclusively) to the mainland. Still, given that maps have not been changed in the wake of the discovery of Madagascar's history, this seems highly unlikely.

However, even if philosophers' intuitions are typical of their contemporaneous community, they might still possibly be out of touch about what reference is because at some point in the distant past, their predecessors stipulated that our term reference pick out a relation something like that presented in Kripke's original picture. We might be living in a $\mathrm{K}$ world in spite of our finding Evans's analysis the most intuitive, because the relevant psychological differences between our being in a $\mathrm{K}$ world or an E world had been, as Cappelan and Winblad suggest, "spread out in time" (1999a, 342). The term reference might, long ago, have undergone the type of "baptism" that Kripke describes, and our intuitions may now simply be out of touch with what the originally baptized reference was. Capplen and Winblad attempt to describe such a case where "Kripke's positive account of reference" applies to "reference" itself:

Just as names and natural kind terms can be introduced by dubbings, so can "reference." One introduces "water" by pointing to some water and saying "water," or saying something like "Let's call the liquid there "water.", Similarly, one might introduce "reference" by pointing out a certain act of referring and saying "reference," or saying something like "Let's call the sort of act he just performed 'reference." "The term would then refer to whatever sort of act that happened to be. [1999a, 339-40]

19 For doubts about the typicality of such intuitions, see Cummins 1998, Stich 1998, Stich and Weinberg 2001, and Weinberg, Nichols, and Stich 2001. This problem is dealt with in more detail in Jackman 2004, though I'll just note here that if intuitions about reference are too diverse, that would be evidence that there was no single thing to analyze, not that there was a unified topic to be analyzed with something other than intuitions.

20 This case is discussed in some detail in Evans 1985. 
Fortunately for our use of intuitions, there are a number of problems with such an analogy.

First of all, extending Kripke's picture this way seems to require both that "reference" be understood as a natural-kind term and that saying something like "Let's call the sort of act he just performed "reference"" would succeed in picking out a unique such kind. Cappelan and Winblad address the issue that reference may turn out not to be a natural kind by pointing out that "externalist" theories that have been defended for many terms that are not natural kinds (1999a, 341-42). In doing so they produce a number of examples of the sort familiar from the work of Tyler Burge. ${ }^{21}$ However, an expert community may be essential for the use of such terms, and this undercuts the response of Cappelan and Winblad to a second objection, that "some people must know what reference consists in," which is to point out that neither experts nor a division of linguistic labor is required on Putnam's account of naturalkind terms (1999a, 341). Consequently, Cappelan and Winblad's response to this second objection makes them vulnerable to the first. When they insist that no one need know what "reference" is (and thus avoid the second objection), they are forced to assimilate "reference" to a term like "water" rather than "junk bond," in which case the first objection (that "reference" is not a natural-kind term) seems well placed. ${ }^{22}$

Still, the sorts of potential gaps in our knowledge that the semantic externalist draws upon might also seem to be found for words that are neither natural-kind terms nor terms for which there is an authoritative expert community. All that Cappelan and Winblad require is that there be a distinction between the "superficial" and "underlying" features associated with the relevant terms (1999a, 341). Such a distinction can be drawn for terms like "pencil," "pediatrician," and "chair," none of which seems to be a natural kind (and most of which clearly lack authoritative experts in our community), but for all of which Putnam presents thought experiments similar to his discussion of Twin Earth (Putnam 1975). However, while the underlying features for natural kinds are not the sort of thing that should be available to a priori reflection, this is less obviously the case with a kind like "pediatrician," where the distinction between comparatively superficial features, such as wearing a white coat, versus more essential features, such as, say, having a medical degree, should be available to the most competent speakers in the community.

${ }^{21}$ See Burge 1979. The particular example they focus on is "junk bond." They also point out that Kripke's account works for proper names as well as natural kinds (341), but since the philosophic terms in questions are not plausibly understood on a model with proper names, this is not a point that will be pursued here.

22 It might thus be better to take the (somewhat implausible, if more consistent) line developed by Devitt (1994) and Kornblith (1998), who simply insist that reference and meaning can be treated a natural kinds. (For criticism of this line of theirs, see Jackman 1996 and Goldman and Pust 1998.) 
Putnam's own discussion of these terms where he imagined pencils turning out to be organisms and pediatricians turning out to be Martian spies are (1) typically found less persuasive than his discussion of water, ${ }^{23}$ and (2) probably best understood as cases where we discover that, in spite of the initial appearances to the contrary, "pencil" and "pediatrician" picked out natural kinds after all. ${ }^{24}$ If this is the case, such examples give us little reason to think that our intuitions about essential properties could be similarly off-base for nonnatural kind terms.

Furthermore, even if "reference" were a natural-kind term, or if Cappelan and Winblad's account didn't require that it be one, there would still be important disanalogies between it and a kind term like "water." For Cappelan and Winblad's assimilation of "reference" to Kripke's baptismal cases to go smoothly, something fitting Kripke's account of reference must have been present at the time of baptism, while nothing satisfying Evans's account was present. Since most instances of $\mathrm{K}$ reference (including all the paradigm cases of it) are also instances of E reference, this seems highly unlikely. Given that Kripke's and Evans's accounts would make the same predictions about most cases, it seems implausible that such a dubbing would serve to pick out one of the two referential relations uniquely. ${ }^{25}$

This is a familiar problem with Kripke's original picture of reference, but the most natural solutions to it (positing more specific referential intentions on the baptizer's part) does not seem likely to underwrite the sorts of case Cappelan and Winblad want to develop. ${ }^{26}$ One could argue that while the case in question was an instance of both $\mathrm{K}$ reference and $\mathrm{E}$

23 Many would argue that (1) if the Martian spies took care of children, it would just be the case that all pediatricians were Martians, and (2) if they never cared for children, it would just be the case that there never had been any pediatricians. In much the same way, if all the pencils we had encountered so far had actually been organisms, this would not prevent an instrument functionally equivalent to those creatures (for the purposes of writing) from being a pencil as well.

24 The importance of the fact that we can't tell a priori what kinds of kind our terms pick out is discussed further in Jackman 2001b. (That article also gives a slightly more nuanced - pessimistic - take on how accessible the essential features of our terms need be to even the most competent speakers, but it does so in a way that is not, ultimately, relevant to the argument here.)

${ }^{25}$ Just as pointing to a pack of dogs and saying "Let's call is these things dogs" will not settle whether the species should be individuated in terms of genetic makeup or evolutionary history.

26 Further, one can't argue (in the manner of Lewis 1983) that one of the relations is somehow more "natural" than the other and thus in a position to determine what reference is. Lewis's suggestion has struck many (including Putnam) as highly implausible, but even if were an acceptable explanation of the problem of determining what sortal was in play at the time of baptism, it would actually tell against the sorts of case that Cappelan and Winblad want to develop. Not only do both $\mathrm{K}$ reference and $\mathrm{E}$ reference seem equally natural, if there were such a natural "ranking" between the two then the more "natural" of the two relations would be what "reference" was in both worlds, so a "semantic Twin Earth" would be ruled out. 
reference, the dubbers' intentions were such that only one of the two would be picked out, but even if (as would be highly unlikely) the baptizer had the appropriately specific intention (or only one of the two relations were instantiated at the time of baptism), it wouldn't matter for the justification of our current intuitions. To think otherwise requires that, just as we intend to refer by "Cicero" to whomever the ancient Romans meant by the name, we would intend to refer by "reference" to whatever some unidentified, and possibly unidentifiable, precursor of ours meant by the term. However, we are typically more interested in talking about just whom the Romans were talking about when we use a name like Cicero than we are when we use more philosophical terms like "virtue" or "reference," where our willingness to admit that we mean something different now from what our predecessors did by the term is considerably higher. ${ }^{27}$ If we have, as I think we do ${ }^{28}$ intuitions about reference that are more in line with Evans's account, the discovery that our precursors had more Kripke-like intuitions about the topic would be interesting, but it would not give us any compelling reason to think that our current intuitions are mistaken.

It does not follow from this that one must deny the "negative" point that someone can use "reference" successfully even if her or she possesses minimal or inaccurate information about reference itself. ${ }^{29}$ Nevertheless, unless some clear analogue of Kripke's positive account can be found for "reference," one should question just how extensive and widespread this inaccurate information could be. The account presented in the following section, for instance, will be able to accommodate the negative point within a framework that still allows the sorts of intuitions to which philosophers appeal to be prima facie justified.

\section{Intuition, Meaning, and Use}

It appears, then, to be far from easy to present a scenario that shows how our semantic intuitions could be radically out of touch with the semantic facts about which they purport to be intuitions. However, one could still argue that semantic externalism provides one with perfectly general

27 There are good reasons to have such intentions with historical terms. The initial users are, after all, the only ones who are aquatinted with the historical subject, and our interest in "Cicero" is often tied to its reference being shared with such users. Even in the social case, we often defer to the use of various "experts" because they have better access to what is being talked about (for a discussion of this, see Burge 1989). Such asymmetries of access do not seem to be as evident with philosophical terms (though recent work on "explanation" suggests that this is not always the case with the philosophy of science, and Cummins 1998 suggests that philosophy of mind should view itself in a similar fashion).

28 As does, apparently, Kripke $(1980,163)$.

${ }^{29}$ The importance of this "negative" point of Kripke's is stressed in Cappelan and Winblad 1999a, 339. 
arguments for breaking the connection between meaning and use that underwrites our reliance on intuitions. Considerations of space don't allow me to deal with this last point in the detail that it deserves, but it is by no means settled that internalist theories of meaning, such as the descriptive theory of reference, are the only accounts of meaning that could legitimate appeals to intuitions in philosophy. ${ }^{30}$

First of all, one should note that the types of intuitions involved when philosophers engage in, say, semantic theory are not intuitions to the effect that something like the descriptive theory of reference is correct. Rather, they are our intuitions about how our semantic vocabulary should be applied in particular (often counterfactual) instances. Theories like the causal and descriptive theory are attempts to account for such intuitions, not the direct result of intuitions themselves. ${ }^{31}$ This should be stressed, since while a causal theory like Evans's will allow that most of our theoretical beliefs about, say, water could be false, it does not allow that most of our applications of the term could be. Indeed, externalist theories typically entail that most of our "that is "water" and "he is Gödel" utterances will turn out to be true. ${ }^{32}$ And it is precisely these sorts of applications that make up the majority of our semantic intuitions. The intuitions that philosophers typically appeal to when engaged in conceptual analysis are primarily about the application of a concept, not "theoretical" intuitions about the concepts in question.

There could thus be cases in which most of the features associated with a semantic term turn out not to apply to whatever is in the term's extension. ${ }^{33}$ However, there could be such cases, because our intuitions relate most centrally to the term's extension, not the "features" we (consciously) associate with it. For instance, if a Scholastic philosopher explained reference in terms of phantasms," it may be that most of the features he associated with the term were mistaken, but this would not change the fact that most of his intuitions about how the term should be applied in various contexts could be roughly the same as ours. The primary constitutive elements here are the judgments about what we would be referring to in various actual and counterfactual situations, not the particular theories by which we try to systematize such intuitions. ${ }^{34}$ When we come to think of an earlier philosopher as providing a defective

30 The point is discussed in greater detail in Jackman 1999 and 2003.

31 While I'm inclined to agree with Kripke's, Putnam's, and Burge's intuitions about the cases they discuss, the legitimacy of such intuitions does not always correlate to the legitimacy of the philosophical theories developed to explain them. (For a useful discussion of this, see Horrowitz 1998.)

32 See Evans 1985, 22-23. This is the reason why semantic externalism is often taken to have certain "antiskeptical" consequences (see Putnam 1981, Davidson 1986, and Burge 1986). For a discussion of some of the limitations to such arguments, see Jackman 2001b.

33 As Cappelan and Winblad stress (1999a, 339).

34 It is precisely the "what we would say" intuitions that Kripke and Putnam rely on. 
analysis, it is usually because of faults in his theories that attempt to systematize his intuitions, not in the intuitions themselves. ${ }^{35}$

Furthermore, one can tie meaning to use without doing so exclusively. Cappelan and Winblad assume that the use of intuitions is only legitimate in semantic theory if, in order to use "reference" meaningfully, "speakers need to have in their minds something that determines uniquely identifying conditions for what is in a term's extension" (1999a, 342). On the other hand, the view defended here suggests that even if use doesn't completely determine meaning, it still may contribute significantly to it. Internalist theories made reference determined entirely by introspectively accessible aspects of use, and thus made intuitions reflecting such use a legitimate source of philosophical knowledge that would be immune to criticisms from other sources. By contrast, while externalist theories do not make what we mean a function of introspectively accessible aspects of use alone, they can still treat meaning as largely a function of use. ${ }^{36}$ The equilibrium one looks for is "wide" in the sense that the equilibrium must take account of the beliefs resulting from ongoing empirical discoveries and theories, but this does not change the fact that many, and in some cases most, of the inputs remain introspectively accessible. ${ }^{37}$ Intuitions about what we would say are thus still partially meaning determining, and so still have some prima facie claim to be correct. ${ }^{38}$ Intuitions are not "guided by conceptual knowledge,"39 but rather get their value by being partially constitutive of their subject matter.

Pessimism about the reliability of intuitions can stem from treating them as if they must be expressive of our implicit knowledge of the concepts in question rather than being partially constitutive of those concepts. This expressive picture is presented by Cappelan and Winblad as the following "concept model" of conceptual analysis:

Philosophers are engaged in the analysis of certain concepts, among them the concepts of knowledge, reference and personhood. Initially, our grasp of these concepts is largely or wholly tacit. What we are attempting to do as

35 This may be less true of ethics than semantics, but even here the disagreements will typically be much more pronounced at the level of theory than at the level of intuitions about cases.

36 This claim is not uncontroversial, and it is discussed and defended in greater detain in Jackman 2003.

37 For a discussion of the difference between "wide" and "narrow" equilibrium, see Daniels 1979 and 1980 and Pust 2000. (The sense of wideness here is, however, tied more to a general holism regarding our commitments, and thus should not be committed to the sorts of "levels" of theory that Daniels incorporates into his account.)

38 Jackman 2003 goes into considerably more detail on how such a "use-based" theory of meaning can account for the prima facie justification of our beliefs while still supporting semantic externalism.

39 As Cappelan and Winblad suggest they might be (1999a, 337). 
philosophers is make this tacit knowledge explicit. Because intuitions about relevant cases are reliably guided by these tacitly known concepts, such intuitions constitute trustworthy evidence for and against philosophical theories. [1999b, 198]

With this reliance on implicit knowledge, the philosopher's use of intuitions can seem much like the linguist's appeal to judgments about the grammaticality of various sentences. Just as the grammaticality judgment is taken to reflect reliably a linguistic rule that is implicitly known, a philosopher's intuitions is taken to reflect reliably his implicitly known concept. ${ }^{40}$ This model is combined with what Cappelan and Winblad refer to as the "Platonic Assumption," to the effect that "we all know the 'right' necessary and sufficient conditions [for the application of our concepts] ... but this knowledge is buried very deep down in our minds and is therefore hard to make explicit" (1999b, 205).

I won't deny that many philosophers who engage in conceptual analysis have presupposed both the concept model and the Platonic assumption, and neither would I deny that these assumptions are highly problematic. ${ }^{41}$ Nevertheless, if one gives up the analogy with linguistics and the expressive interpretation of conceptual analysis, the more constitutive understanding of the practice still remains available to underwrite its reliability. We need not think that there must always be coherent concepts lying behind our usage (indeed, we have quite compelling evidence that there isn't), ${ }^{42}$ but neither must we think that in such cases a coherent concept can't be constructed out of our use. ${ }^{43}$

Semantic externalism doesn't entail that what we mean by our terms is completely independent of the beliefs that we associate with them, and so long as what we mean is still, in some sense, a function of what we believe, our intuitions will have at least prima facie value when analyzing various concepts. On a constitutive account that relies on wide reflective equilibrium, our intuitions may turn out to be revisable in the light of empirical evidence. ${ }^{44}$ This doesn't mean that appeals to intuitions would not be

40 For a recent defense of this analogy between philosophy and linguistics, see Miscevic 2000.For reasons for questioning the fruitfulness of such an analogy, see Daniels 1980 and DePaul 2000.

41 See, for instance, the discussion in Jackman 2001a.

42 For a discussion of this, see Jackman 2004.

43 Conceptual analysis is, on this view, both a constructive and a normative practice. (For a recent example of analysis that self-consciously takes this approach, see the discussion of "knowledge" in Williams 2001). Furthermore, there are reasons for thinking that are rationally committed to engaging in such constructive projects, and for a discussion of these, see Jackman (forthcoming).

${ }^{44}$ Fallibilism is compatible with constitution if one is the right sort of holist about the relation between the constituting elements and the constituted objects. Very roughly put, a constitutive element can be understood as mistaken if it is out of line with a more central cluster of constitutive elements. 
justified, or that theories that rely on them can't be known a priori. ${ }^{45}$ Judgments based on intuitions always have, as a matter of fact, been so revisable (since they could later be discovered to conflict with other more deeply entrenched intuitions). The main point is that they are suited to serve as legitimate inputs when philosophers are trying to reach reflective equilibrium about a concept. Finding such an equilibrium may be a collective enterprise, and there is no reason to think that conceptual analysis shouldn't be an important part of it.

The constitutive nature of the intuitions in question also explains why they are of use in spite of their fallibility. Fallibilistic intuitions could conflict, and the falliblist intuitionist must thus respond to Ayer's challenge that "unless it is possible to provide some criterion by which one might decide between conflicting intuitions, a mere appeal to intuition is worthless as a test of a proposition's validity" (1946, 106). One could hope that the differences among people's intuitions may be removed through the process of reaching an equilibrium among these initial intuitions, but such convergence may not arrive if the surrounding intuitions of the two thinkers differ as well. As Steven Hales puts it, "If there is no way for the two opponents to settle their differences except by appeal to yet more intuitions that again conflict, then they have reached an epistemic impasse. Since they cannot both be right, the method of 'pure reason' has proven useless in finding the truth" $(2000,183){ }^{46}$ However, if the lack of convergence is not the result of the two subjects having failed to reach an equilibrium among their intuitions, and each has a coherent and consistent set of commitments relating to the terms in question, why should we accept Hales's assumption that "they cannot both be right"? There is nothing incoherent in assuming that two people could ultimately turn out to mean different things by terms like "person," "knowledge," and "meaning," and the two speakers' ability to reach nonconvergent equilibria relating to these terms would suggest that we are dealing with such a case. The only sense in which either of the two debaters would be mistaken would be in their assumption that they are talking about the same thing. ${ }^{47}$

${ }^{45}$ To think otherwise would be to think that things that are justified a priori can't be revised based on empirical discoveries. Justification doesn't require certainty, and this is no different with a priori justification. (For a discussion of this, see Peacocke and Boghossian 2000.) Still, the possibility of this sort of correction, and the general holism that goes with it, suggests that the intuitions that philosophers rely on should not be understood as the sorts of "rational intuitions" posited by, among others, Hales $(2000,135)$.

46 This is from Hales's discussion of the passage from Ayer cited above. For a similar line of criticism, see Cummins 1998, 115.

${ }^{47}$ For a discussion of the possibility that this may be the norm in metaphysical and metasemantic debates, see Lynch 1998 and Jackman 1996. The pessimism about intuitions would thus ultimately stem from a semantic analogue of something like the "epistemological realism" criticized in Williams 1991 and 2001. For a dissenting view about the possibility of such pluralism, see Kornblith 1998. 
One might worry that there is something unhappily circular about justifying appeals to intuitions by means of a theory of meaning that is itself justified by means of appeals to intuitions. ${ }^{48}$ Nevertheless, this circularity is only vicious if we face a standing requirement to justify our use of intuitions, rather than a more local call for justification arising from specific reasons for thinking them unreliable. ${ }^{49}$ One such reason for doubting the reliability of intuitions would be if, as Cappelan and Widblad argue, the semantic theories supported by our intuitions suggested that they should not be reliable. ${ }^{50}$ That kind of tension would amount to an internal inconsistency in our intuitions that would undermine the justification of our use of them. However, this sort of challenge can be met by showing (as this article has attempted to do) that our intuitions are not inconsistent in the suggested way, and that our intuitions about semantics should ultimately lead us to think that our intuitions are generally reliable. Such arguments for consistency are not viciously circular in the way that similar arguments would be if they were offered as replies to a bare demand to show that intuitions are legitimate.

\section{Conclusion}

Within the sort of "use-theoretic" framework outlined above, our intuitions about when our terms and concepts are correctly applied play an essential role in determining what those concepts are. Consequently, our intuitions are reliable in virtue of being at least partially constitutive of what they purport to be intuitions about. Indeed, they may have a particularly large constitutive role in many philosophically central concepts. While the conceptual intuitions (and the analyses that result from them) will have to be recognized as fallible, they still have a prima facie claim to correctness. A naturalistic and externalistic account of concepts thus merely requires that the methodology of conceptual analysis be reinterpreted (from a "Platonic" to a "constructive" model) rather than be given up.

${ }^{48}$ See Cappelan and Winblad 1999b, 212, for a version of this worry. It can also be found in Hales 2000, 138-39, coupled with the suggestion that endorsing a type of classical foundationalism about certain intuitions would be our only way out of the circle.

${ }^{49}$ I take this "Peircian" conception of justification to go with the sorts of fallibilism outlined above. This "default and challenge" conception of justification is not universally shared, but it is not within the scope of this article to defend it here. (Though see Brandom 1994 and Williams 1991 and 2001.) One can find related attempts to cast of the burden of proof with respect to intuitions in Bealer 1996 and Tidman 1996, and these two defenses are criticized in Hales 2000, 140, 144.

${ }^{50}$ Since the critic of intuitions is at his strongest when presenting a reductio (as noted in Cummins 1998), it is not enough simply to point out that such critics rely on intuitions themselves. (For a well-developed version of this later strategy, see Pust 2000.) 
Department of Philosophy

York University

4700 Keele Street

Toronto, ON M3J 1 P3

Canada

hjackman@yorku.ca

\section{Acknowledgments}

I'd like to thank Herman Cappelan, Douglas Winblad, Benjamin Sheffield Cordry, and audiences at the 2002 meeting of he Ontario Philosophical Society, the 2002 Mid-South Philosophy Conference, and the 2002 meeting of the Central Division of the American Philosophical Association for comments on earlier versions of this article.

\section{References}

Ayer, A. J. 1946. Language, Truth and Logic. 2d edition. New York: Dover Original edition published in 1936.

Bealer, George. 1996. "On the Possibility of Philosophical Knowledge." In Metaphysics, volume 10, Philosophical Perspectives, edited by J. E. Tomberline, 1-34. Oxford: Blackwell.

Brandom, R. 1994. Making It Explicit. Cambridge, Mass.: Harvard University Press.

Burge, T. 1979. "Individualism and the Mental." In Midwest Studies in Philosophy IV: Studies in Metaphysics, edited by Peter French, Theodore E. Uehling and Howard K. Wettstein. Minneapolis: University of Minnesota Press 73-121.

- 1986. "Cartesian Error and the Objectivity of Perception." In Subject, Thought, and Context, edited by Philip Pettit and John McDowell, 117-36. New York: Oxford University Press.

- 1988. "Individualism and Self-Knowledge." Journal of Philosophy 85, no. 11:649-63.

. 1989. "Wherein Is Language Social?” In Reflections on Chomsky, edited by Alexander George, 175-91. Oxford: Blackwell.

Boghossian, P., and C. Peacocke. 2000. "Introduction." In New Essays on the A Priori, edited by Paul Boghossian and Christopher Peacocke, 1-10. New York: Oxford University Press.

Cappelan, H., and D. Winblad. 1999a. " 'Reference' Externalized and the Role of Intuitions in Semantic Theory." American Philosophical Quarterly 36, no. 4 (Oct.):337-50.

. 1999b. "Intuitions." Facta Philosophica 1, no. 1:197-216.

Cummins, R. 1998. "Reflection on Reflective Equilibrium." In DePaul and Ramsey 1998a, 113-27.

Daniels, N. 1979. "Wide Reflective Equilibrium and Theory Acceptance in Ethics." Journal of Philosophy 76:256-82. 
1980. "On Some Methods of Ethics and Linguistics." Philosophical Studies 37:21-36.

Davidson, D. 1984. "First Person Authority." Dialectica 38, nos. 2-3: $101-11$.

. 1986. "A Coherence Theory of Truth and Knowledge." In Truth and Interpretation, edited by Ernest Lepore, 307-19. Oxford: Blackwell.

DePaul, M. 2000. "Linguistics Is Not a Good Model for Philosophy." In Henderson and Horgan 2000, 113-20.

DePaul, M., and W. Ramsey eds. 1998a. Rethinking Intuition: The Psychology of Intuition and Its Role in Philosophical Inquiry. Lanham, Md.: Rowman and Littlefield.

DePaul, M., and W. Ramsey. 1998b. Preface to Rethinking Intuition: The Psychology of Intuition and Its Role in Philosophical Inquiry. In DePaul and Ramsey 1998a, vii-xvi.

Devitt, M. 1994. "The Methodology of Naturalistic Semantics." Journal of Philosophy 91, no. 10 (Oct.):545-72.

Donnellan, K. 1983. "Kripke and Putnam on Natural Kind Terms." In Knowledge and Mind, edited by Carl Ginet and Sidney Schoemaker, 84-104. New York: Oxford University Press.

- 1990. "Belief and the Identity of Reference." In Propositional Attitudes: The Role of Content in Logic, Language, and Mind, edited by C. Anthony Anderson and Joseph Owens, 201-14. Stanford: Center for the Study of Language and Information.

Evans, G. 1985. "The Causal Theory of Names." In Collected Papers, 1-24. New York: Oxford University Press. First published in 1973.

Goldman, A., and J. Pust. 1998. "Philosophical Theory and Intuitional Evidence." In DePaul and Ramsey 1998a, 179-97.

Goodman, N. 1983. Fact, Fiction, and Forecast. Fourth edition. Cambridge, Mass.: Harvard University Press. Original edition published in 1954.

Gutting, G. 1998. " 'Rethinking Intuition': A Historical and Metaphilosophical Introduction.” In DePaul and Ramsey 1998a, 3-13.

Hales, S. D. 2000. "The Problem of Intuition." American Philosophical Quarterly 37, no. 2 (April):135-47.

Henderson, D., and T. Horgan eds. 2000. "The Role of the Empirical (and of the A Priori) in Epistemology." Southern Journal of Philosophy, 38, Supplement.

Horrowitz, T. 1998. "Philosophical Intuitions and Psychological Theory." In DePaul and Ramsey 1998a, 143-60.

Jackman, H. 1996. "Semantic Norms and Temporal Externalism." Ph.D. dissertation, University of Pittsburgh. (Available at www.jackman. org.)

_. 1999. "Moderate Holism and the Instability Thesis." American Philosophical Quarterly 36, no. 4 (Oct.):361-69.

- 2001a. "Ordinary Language, Conventionalism, and A Priori Knowledge." Dialectica 55, no. 1:1-11. 
2001b. "Semantic Pragmatism and A Priori Knowledge." Canadian Journal of Philosophy 31, no. 4 (Dec.):455-80.

- 2003. "Charity, Self-Interpretation, and Belief." Journal of Philosophical Research 28:145-70.

- 2004a. "Intuitions and Psychological Theory." Manuscript, York University.

- 2004b. "Temporal Externalism and Epistemic Theories of Vagueness." Philosophical Studies 17, nos. 1-2 (January):79-94.

Kornblith, H. 1998. "The Role of Intuition in Philosophical Inquiry: An Account with No Unnatural Ingredients." In DePaul and Ramsey 1998a, 129-41.

Kripke, S. 1980. Naming and Necessity. Cambridge, Mass.: Harvard University Press From an article first published in 1972.

Laurence, S., and E. Margolis. "Concepts and Conceptual Analysis." Philosophy and Phenomenological Research 67, no. 2:253-82.

Lewis, D. 1983. "New Work for a Theory of Universals." Australasian Journal of Philosophy 61, no. 4:343-77.

Lynch, M. 1998. Truth in Context. Cambridge, Mass.: MIT Press.

Miscevic, N. 2000. "Intuitions as a Second Window." In Henderson and Horgan 2000, 87-112.

Pust, J. 2000. Intuitions as Evidence. New York: Garland.

Putnam, H. 1975. "The Meaning of 'Meaning.', In Mind, Language and Reality, 215-71. New York: Cambridge University Press.

- 1981. Reason, Truth and History. New York: Cambridge University Press.

Rawls, J. 1971. A Theory of Justice. Cambridge, Mass.: Harvard University Press.

Searle, J. 1967. "Proper Names." In Philosophical Logic, edited by P. F. Strawson, 89-96. New York: Oxford University Press. Original published in 1958.

Sosa, E. 2000. "Modal and Other A Priori Knowledge: How Can We Know What Is Possible and What Is Impossible?' In Henderson and Horgan 2000, 1-16.

Stich, S. 1998. "Reflective Equilibrium, Analytic Epistemology, and the Problem of Cognitive Diversity." In DePaul and Ramsey 1998a, 95-112.

Stich, S., and J. Weinberg. 2001. "Jackson's Empirical Assumptions." Philosophy and Phenomenological Research 62, no. 3 (May):637-43.

Tidman, P. 1996. "The Justification of A Priori Intuitions." Philosophy and Phenomenological Research 56, no. 1:161-71.

Weinberg, J., S. Nichols, and S. Stich. 2001. "Normativity and Epistemic Intuitions." Philosophical Topics 29:429-60.

Williams, M. 1991. Unnatural Doubts. Oxford: Blackwell. 2001. Problems of Knowledge. New York: Oxford University Press. 


\section{Author Query Form}

\section{Journal META}

\section{Article $\quad 03603007$}

Dear Author,

During the copy-editing of your paper, the following queries arose. Please respond to these by marking up your proofs with the necessary changes/additions. Please write your answers on the query sheet if there is insufficient space on the page proofs. Please write clearly and follow the conventions shown on the attached corrections sheet. If returning the proof by fax do not write too close to the paper's edge. Please remember that illegible mark-ups may delay publication

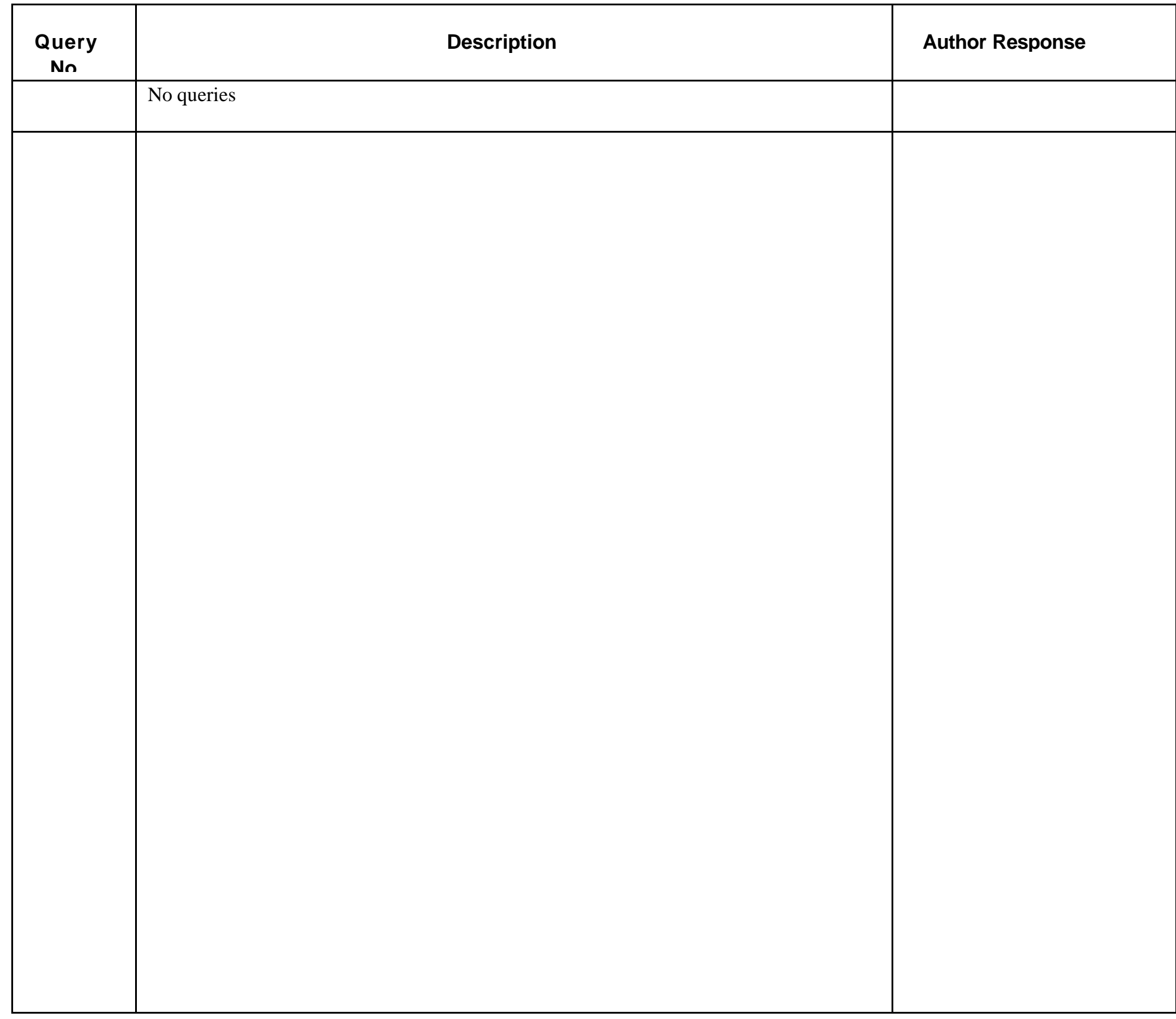

